\title{
A Rat Model for Choroidal Neovascularization Using Subretinal Lipid Hydroperoxide Injection
}

\author{
Takayuki Baba, ${ }^{*}$ Imran A. Bhutto, ${ }^{*}$ Carol Merges, ${ }^{*}$ \\ Rhonda Grebe, ${ }^{*}$ David Emmert, ${ }^{*}$ \\ D. Scott McLeod, ${ }^{\star}$ Donald Armstrong, ${ }^{\dagger}$ \\ and Gerard A. Lutty*

\begin{abstract}
From the Wilmer Ophthalmological Institute," The Johns Hopkins University, School of Medicine, Baltimore, Maryland; and the Department of Ophthalmology, ${ }^{\dagger}$ University of Florida,
\end{abstract} \\ Gainesville, Florida
}

The purpose of this study was to develop and characterize a rat model of choroidal neovascularization (CNV) as occurs in age-related macular degeneration. The lipid hydroperoxide $13(S)$-hydroperoxy- $9 Z, 11 E$ octadecadienoic acid (HPODE) is found in submacular Bruch's membrane in aged humans and has been reported to generate neovascularization in a rabbit model. Three weeks after a single subretinal injection of $30 \mu \mathrm{g}$ of HpODE, eyes of Sprague-Dawley rats were harvested. Follow-up fluorescein angiography was done on other animals until 5 weeks postinjection. Histological studies, immunohistochemical staining, and flatmount choroids for CNV measurements were performed. In addition, we used murine neuronal, bovine endothelial, and human ARPE19 cells for testing the in vitro effects of HpODE. CNV developed in $\mathbf{8 5 . 7 \%}$ of $\mathrm{HpODE}$-injected eyes. The neovascular areas were significantly greater in HpODE-injected eyes compared with those in control eyes $(P=0.023)$. The CNV had maximum dye leakage at 3 weeks, which subsided by the 5th week. Histologically, CNV extended from the choriocapillaris into the subretinal space. ED1-positive macrophages were recruited to the site. In vitro assays demonstrated that only 30 $\mathrm{ng} / \mathrm{ml}$ HpODE induced cell proliferation and migration of endothelial cells. HpODE-induced CNV was highly reproducible, and its natural course seems to be ideal for evaluating therapeutic modalities. Because HpODE has been isolated from aged humans, the HpODE-induced rat model seems to be a relevant experimental model for $\mathrm{CNV}$ in age-related macular degeneration. (Am J Pathol 2010, 176:3085-3097; DOI: 10.2353/ajpath.2010.090989)
Age-related macular degeneration (AMD) is the leading cause of central vision loss for populations older than 65 years in developed countries. ${ }^{1}$ There are two major types of AMD: dry and wet (or exudative). One type of dry AMD is geographic atrophy, which is the atrophy of the retinal pigment epithelium (RPE) in a well defined area centered on the fovea. Wet AMD progresses faster and results in more severe visual loss. In wet AMD, choroidal neovascularization (CNV) is associated with many pathological changes such as subretinal hemorrhage, serous retinal detachment, fibrovascular and serous pigment epithelium detachment, and subretinal scar formation. Both forms of AMD have characteristic extracellular lesions (drusen and basal linear and laminar deposits) that have an impact on RPE and photoreceptor viability and health. ${ }^{2,3}$

An experimental model is essential to investigate the nature and treatment of CNV. The first experimental CNV model of Ryan and his colleagues was reported in 1979. ${ }^{4}$ They attempted to generate CNV using three different methods in monkeys. Their hypothesis was that disruption of Bruch's membrane induces neovascularization from choroid. According to their report, mechanical/enzymatic disruption of Bruch's membrane (BrM) via transscleral and transvitreal injections resulted in a low incidence of CNV (8.9 and 12.5\%). Laser-induced disruption of BrM eventually produced CNV at a higher rate (80\%), and the authors hypothesized that subretinal scar formation after laser treatment ${ }^{5}$ was the stimulus for CNV formation. However, the laser-induced CNV model itself was

Supported by National Institutes of Health (grants R01-016151 to G.A.L. and EY-01765 to Wilmer) and by the Altsheler-Durell Foundation. T.B. was a Bausch and Lomb Japan Vitreoretinal Research Fellow, an Uehara Memorial Foundation Research Fellow, and a Japan Society for the Promotion of Science Postdoctoral Fellow for Research Abroad. G.A.L. received a Research to Prevent Blindness Senior Scientific Investigator Award in 2008.

Accepted for publication February 9, 2010

A part of this study was presented at Association for Research in Vision and Ophthalmology Annual Meeting, May 3-7, 2009: Fort Lauderdale, FL.

Address reprint requests to Gerard A. Lutty, Ph.D., G. Edward and G. Britton Durell Professor of Ophthalmology, Wilmer Ophthalmological Institute, M041 Smith Building, Johns Hopkins Hospital, 400 North Broadway, Baltimore, MD 21287. E-mail: galutty@jhmi.edu. 
traumatic and was related to AMD only by the denominator of subretinal neovascularization. Laser-induced CNV has also been shown to regress spontaneously in a period of 3 weeks. ${ }^{6}$

Lipid deposition in Bruch's membrane (BrM) and deposits (drusen) associated with Bruch's membrane in AMD are now well documented. ${ }^{7,8} 13(S)$-Hydroperoxy9Z,11E-octadecadienoic acid (HpODE) is one of several oxidized lipids, which exist under normal conditions in cell membranes of the human body. This and other peroxidized lipids were reported to be elevated in aged BrM. ${ }^{9}$ In 2002, Tamai et $\mathrm{al}^{10}$ developed an animal model for neovascularization using HpODE that they synthesized from linoleic acid. ${ }^{11}$ They injected HpODE into the subretinal space of rabbits and observed a high incidence of CNV. Compared with laser injury, this method seems to have less adverse effects such as severe inflammation and is initiated by a physiologically natural material in aged BrM. Therefore, this CNV model may more closely mimic the clinical situation of wet AMD than laser injury. Unfortunately, Tamai et al could not address the exact mechanism by which HpODE gives rise to CNV. In terms of expense and ease in maintaining smaller rodents, use of rat or mouse would be helpful both for basic investigations of CNV and for studies of its modulation. In the present study, we evaluated whether rats develop CNV after subretinal injection of HpODE. We also investigated the characteristics of this CNV model and elucidated how HpODE functions on the development of $\mathrm{CNV}$ in vivo and in vitro.

\section{Materials and Methods}

A total of 28 male Sprague-Dawley rats (6 to 8 weeks of age) obtained from Harlan Laboratories Inc. (Frederick, $\mathrm{MD})$ were used in this study. All animals weighed between 150 and $200 \mathrm{~g}$ and were housed at constant temperature $\left(20 \pm 1{ }^{\circ} \mathrm{C}\right)$ and humidity $(50 \pm 5 \%)$. They were fed standard rat chow and allowed water ad libitum. All experimental and animal care procedures were performed in compliance with the guideline for Care and Use of Laboratory Animals (Johns Hopkins University) and the Association for Research in Vision and Ophthalmology statement for the Use of Animals in Ophthalmic and Visual Research.

HpODE or 13(S)-hydroperoxy-9Z,11E-octadecadienoic acid [13(S)-HpODE] (Cayman Chemical, Ann Arbor, MI) was provided in ethanol, which was evaporated under nitrogen gas, and then diluted in sterile $0.02 \mathrm{~mol} / \mathrm{L}$ sodium borate buffer, pH 9.0 (calcium- and magnesiumfree), and used immediately after preparation. For study of the dose-dependent CNV response, 1, 5, 15, and 30 $\mu \mathrm{g}$ of HpODE were used. Borate buffer alone was used as a negative control. Animals were sacrificed with an overdose of i.p. pentobarbital, and eyes were processed for analysis at the following time periods after injection: 3 days and 1,2, 3 , and 5 weeks. Table 1 shows a summary of the ocular injections for these studies.
Table 1. Preparation of Eyes for the Study

\begin{tabular}{|c|c|c|c|c|}
\hline Time & $\begin{array}{l}\text { Injected } \\
\text { material }\end{array}$ & $\begin{array}{l}\text { Dose } \\
(\mu \mathrm{g})\end{array}$ & $\begin{array}{l}\text { No. of } \\
\text { eyes }\end{array}$ & $\begin{array}{l}\text { Preparation } \\
\text { (eyes) }\end{array}$ \\
\hline 3 days & $\begin{array}{l}\mathrm{HpODE} \\
\mathrm{BB}\end{array}$ & 30 & $\begin{array}{l}4 \\
2\end{array}$ & JB4 (1), Cryo (3) \\
\hline 1 week & HpODE & 30 & 6 & $\begin{array}{c}\text { JB4 (1), Cryo (3), } \\
\text { TEM (2) }\end{array}$ \\
\hline 2 weeks & $\begin{array}{l}\text { BB } \\
\text { HpODE }\end{array}$ & 30 & $\begin{array}{l}2 \\
6\end{array}$ & $\begin{array}{l}\text { Cryo (1), TEM (1) } \\
\text { JB4 (1), Cryo (3), } \\
\text { TEM (2) }\end{array}$ \\
\hline 3 weeks & $\begin{array}{l}\text { BB } \\
\text { HpODE } \\
\text { HpODE } \\
\text { HpODE } \\
\text { HpODE }\end{array}$ & $\begin{array}{r}1 \\
5 \\
15 \\
30\end{array}$ & $\begin{array}{r}3 \\
2 \\
3 \\
2 \\
14\end{array}$ & $\begin{array}{l}\text { Flat (2) } \\
\text { Flat (3) } \\
\text { Flat (2) } \\
\text { JB4 (2), Flat (9), } \\
\quad \text { Cryo (2), TEM (1) }\end{array}$ \\
\hline & BB & & 7 & $\begin{array}{l}\text { JB4 (1), Flat (5), } \\
\text { TEM (1) }\end{array}$ \\
\hline 5 weeks & $\begin{array}{l}\text { HpODE } \\
\text { BB }\end{array}$ & 30 & $\begin{array}{l}2 \\
2\end{array}$ & $\begin{array}{l}\text { JB4 (1), Flat (1) } \\
\text { JB4 (1), Flat (1) }\end{array}$ \\
\hline
\end{tabular}

BB, borate buffer; JB4, glycol methacrylate plastic-embedded whole eyes; Cryo, cryopreservation; TEM, transmission electronic microscopy; Flat, flatmount.

\section{Subretinal Injection of HpODE}

Subretinal injections were performed in both eyes using a Pico-Injector (PLI-100, Harvard Apparatus, Holliston, MA). Rats were anesthetized by i.p. injection of ketamine/ xylazine $(80 \mathrm{mg} / \mathrm{kg}$ ketamine $+16 \mathrm{mg} / \mathrm{kg}$ xylazine in $0.9 \% \mathrm{NaCl}), 100 \mu \mathrm{l} / 100 \mathrm{~g}$ b.wt. The pupils were dilated with 2.5\% Phenylephrine Hydrochloride Ophthalmic solution (AK-DILATE, Akorn, Buffalo Glove, IL) followed by 0.5\% Tetracaine Hydrochloride Ophthalmic solution (Phoenix Pharmaceutical Inc., St. Joseph, MO) eye drops as topical anesthesia just before the subretinal injection. The conjunctiva adjacent to the cornea was grasped with forceps to allow optimal exposure of the injection site and stabilize the eye. After making a hole at the pars plana with a 27-gauge sterile needle (BD, Franklin Lakes, NJ), a micropipette glass needle (tip internal diameter 25 to 30 $\mu \mathrm{m})$ mounted on a Pico-Injector holder was inserted through the hole into the vitreous, stopping at the surface of the retina. Two microliters of the HpODE and/or borate buffer was delivered into the subretinal space. Subretinal injections were made under direct observation using a OPMI VISU 200 surgical microscope (Zeiss, Göttingen, Germany). The injected fundus area appeared as a retinal bleb or retinal detachment. Antibiotics (bacitracin zinc and polymyxin B sulfate, AK-Poly-Bac, Akorn) were used in the postoperative period for 3 days. We excluded eyes with subretinal hemorrhage from our study because $100 \%$ of eyes with subretinal hemorrhage had CNV regardless of the material injected (data not shown).

\section{Follow-Up Examination with Fluorescein Fundus Angiography}

Fluorescein angiography was done on some animals using a Spectralis HRA+OCT (Heidelberg, Heidelberg, Germany) every week after the subretinal injection until the 5th week. After being anesthetized with ketamine/ 
xylazine, the pupils were dilated, and a contact lens (Ocular Instruments, Bellevue, WA) was placed on the cornea during angiography. Then $0.1 \mathrm{ml}$ of $10 \%$ sodium fluorescein (Fluorescite, Alcon Laboratories, Fort Worth, TX) was injected into the penile vein.

\section{Tissue Preparation}

Immediately after enucleation, the eyes were fixed in 2\% paraformaldehyde in Tris-buffered saline (TBS) $(\mathrm{pH} 7.4)$ for 1 hour at room temperature. After fixation, the anterior segment was removed and neurosensory retina was separated from the eyecup after placing a notch at the 12 o'clock position of the eye for orientation. Flatmount retina and choroid with attached RPE (eyecup) were prepared after incubation of both tissues with Griffonia simplicifolia agglutinin-I-B4 (GSA)-lectin.

For JB4 and transmission electron microscopy embedding, eyes were fixed in $2.5 \%$ glutaraldehyde/ $2 \%$ paraformaldehyde in $0.1 \mathrm{~mol} / \mathrm{L}$ cacodylate buffer, $\mathrm{pH} 7.4$, overnight at $4^{\circ} \mathrm{C}$. After fixation, the anterior segment was removed, and the specific area of injection (usually nasal quadrant of the eyecup) was excised and used for embedding.

\section{Flatmount Tissue for Imaging of CNV}

GSA-lectin was used for labeling blood vessels according to previous reports. ${ }^{12}$ After washing with TBS and TBS with 1\% Triton-X (Fisher Scientific, Fair Lawn, NJ), the tissues were incubated with biotinylated GSA-lectin (1:100, Sigma-Aldrich, St. Louis, MO) overnight at $4^{\circ} \mathrm{C}$. The next day, streptavidin AF546 (1:50, Invitrogen, Carlsbad, CA) was applied overnight at $4^{\circ} \mathrm{C}$. After washing in TBS, the flatmount tissues were observed with a confocal microscope LSM510 (Carl Zeiss Inc., Thornwood, NY) in the Wilmer Imaging Core Facility. The CNV area was measured using software (version 4.2 SP1) provided with the confocal microscope.

\section{Cryosectioning of Eyes}

The eyecup including the area where the injection was performed was cryopreserved. Tissues were washed in $0.1 \mathrm{~mol} / \mathrm{L}$ sodium phosphate buffer with increasing concentrations of sucrose $(2: 1,1: 1$, and $1: 2$ mixture of $5 \%$ sucrose/20\% sucrose as reported previously). ${ }^{13}$ The eyecups were kept at room temperature for 2 hours in 0.1 $\mathrm{mol} / \mathrm{L}$ sodium phosphate buffer containing $20 \%$ sucrose. The tissue was infiltrated for 30 minutes at room temperature and cryoembedded in a solution consisting of a 2:1 mixture of $20 \%$ sucrose in $0.1 \mathrm{~mol} / \mathrm{L}$ phosphate buffer/ OCT compound (TissueTek, Baxter Scientific, Columbia, $\mathrm{MD}$ ), and stored at $-80^{\circ} \mathrm{C}$. Eight-micrometer-thick cross sections were cut on a Microm HM500M cryostat (Global Medical Instrumentation, Ramsey, MI) at $-25^{\circ} \mathrm{C}$.

\section{PAS and Hematoxylin Staining}

After cryosections were treated with absolute methanol for 5 minutes at $-20^{\circ} \mathrm{C}$ and allowed to air dry, sections were treated with $0.5 \%$ periodic acid for 5 minutes. After washing in distilled water, sections were placed in Schiff's reagent for 10 minutes and developed in several changes of tap water. Sections were then overlaid with Harris' hematoxylin for 2 minutes. After washing in tap water, the sections were blued in saturated lithium carbonate, rinsed in distilled water, and coverslipped in Kaiser's glycerogel.

\section{Oil Red O Staining of Lipids}

Cryopreserved sections were treated in $70 \%$ ethanol for 5 minutes and stained for 12 minutes at $60^{\circ} \mathrm{C}$ with $0.5 \%$ Oil Red $\mathrm{O}$ saturated in $70 \%$ ethanol in a moist chamber. After washing with PBS, nuclei were counterstained with Harris' hematoxylin for 2 minutes. The sections were coverslipped in Kaiser's glycerogel after washing. To verify the specificity of the Oil Red O staining, some sections were extracted with $1 \% \mathrm{HCl}$ in 2:1 chloroform/methanol for 30 minutes as reported by Malek et al. ${ }^{14}$

\section{Streptavidin Alkaline Phosphatase Immunohistochemistry on Cryopreserved Tissue}

Streptavidin alkaline phosphatase (APase) immunohistochemistry was performed on sections of cryopreserved tissue using a nitroblue tetrazolium development system that we described previously. ${ }^{15}$ In brief, 8- $\mu$ m-thick cryosections were permeablized with absolute methanol and blocked with $2 \%$ normal goat serum in TBS $(\mathrm{pH} 7.4)$ with $1 \%$ bovine serum albumin. After washing in TBS, the sections were also blocked with an avidin-biotin complex (ABC) blocking kit (Vector Laboratories, Inc., Burlingame, CA). Tissues were then incubated overnight at $4^{\circ} \mathrm{C}$ with one of the primary antibodies listed in Table $2^{16-19}$ at the stated titer or with isotype and protein concentrationmatched nonimmune IgGs. After washing in TBS, sections were incubated for 30 minutes at room temperature with the biotinylated secondary antibodies diluted 1:500 (KPL, Gaithersburg, MD). Finally, sections were incubated with streptavidin-APase (KPL), and APase activity was developed using a BCIP/NBT kit (Vector Laboratories, Inc.) with the addition of $1 \mathrm{mmol} / \mathrm{L}(-)$-tetramisole $\mathrm{HCl}$ (Sigma-Aldrich), yielding a blue reaction product at sites of antibody binding. After washing, coverslips were applied with Kaiser's glycerogel.

\section{JB4 Embedded Tissue}

Fixed tissues were washed in $5 \%$ sucrose $/ 0.1 \mathrm{~mol} / \mathrm{l} \mathrm{ca-}$ codylate buffer and dehydrated in a series of $30,50,70$, 80 , and 90 and twice in 95\% ethanol for 10 minutes. The tissues were then embedded in JB4 (Polysciences, Warrington, $\mathrm{PA}$ ) under vacuum for 1.5 hours and polymerized at $50^{\circ} \mathrm{C}$ overnight. The $2.5-\mu \mathrm{m}$-thick sections were cut with a glass knife on a Sorvall NT2 microtome (DuPont Instruments, Newton, CT). Images of the fundus and fluorescein angiography helped to orient the injected area to the block face. The sections were stained by 
Table 2. Summary of Antibodies for Immunohistochemistry

\begin{tabular}{|c|c|c|c|c|}
\hline Protein & Function & Marker for & Antibody, manufacturer, titer & Reference \\
\hline CD68 (ED1) & $\begin{array}{l}\text { Glycoprotein on lysosomal } \\
\text { membrane of myeloid } \\
\text { cells }\end{array}$ & $\begin{array}{l}\text { Macrophages, monocytes, weakly } \\
\text { peripheral blood granulocytes }\end{array}$ & $\begin{array}{l}\text { Mouse anti-rat CD68, 1:200 } \\
\quad(\text { AbD Serotec, Raleigh, NC) }\end{array}$ & 16 \\
\hline CD163 (ED2) & Cell surface glycoprotein & $\begin{array}{l}\text { Microglial cells, resident tissue } \\
\text { macrophages, but not } \\
\text { monocytes }\end{array}$ & $\begin{array}{l}\text { Mouse anti rat CD163, 1:200 } \\
\text { (AbD Serotec, Raleigh, NC) }\end{array}$ & 17,18 \\
\hline vWF & $\begin{array}{l}\text { Glycoprotein in plasma, } \\
\text { endothelium, } \\
\text { megakaryocytes }\end{array}$ & $\begin{array}{l}\text { Vascular endothelial cells or } \\
\text { megakaryocytes }\end{array}$ & $\begin{array}{l}\text { Rabbit anti human vWF, 1:5000 } \\
\text { (Dako, Carpinteria, CA) }\end{array}$ & 19 \\
\hline
\end{tabular}

treating with $1 \%$ periodic acid for 2 hours followed by Schiff's reagent (Sigma-Aldrich) for 2 hours at room temperature. After washing and drying overnight, slides were stained with Harris' hematoxylin for 1 hour and coverslipped with Permount (Fisher Scientific).

\section{Transmission Electronic Microscopy}

Eyes harvested at 1,2 , and 3 weeks after subretinal injection were processed for transmission electron microscopy. Tissue from an eye without injection was used as control. After removal of the anterior segment and cutting of a calotte that included the injected lesion, the fixed tissue was washed in $0.05 \mathrm{~mol} / \mathrm{L}$ cacodylate buffer and postfixed in $1 \% \mathrm{OsO}_{4}$ in $0.05 \mathrm{~mol} / \mathrm{L}$ cacodylate buffer for 90 minutes. After washing in $0.05 \mathrm{~mol} / \mathrm{L}$ cacodylate buffer, tissues were dehydrated in 50, 70, 80, 95, and $100 \%$ ethanol and then were stained with $1 \%$ uranyl acetate in $100 \%$ ethanol. The tissue was placed in propylene oxide twice for 15 minutes each time and then was kept overnight in a 1:1 propylene oxide/resin mixture. The tissue was infiltrated in $100 \%$ LX112 resin (Ladd Research Industry, Burlington, VT) for 4 to 6 hours under vacuum, embedded in a final change of $100 \%$ LX112 resin, and then polymerized at $60^{\circ} \mathrm{C}$ for 36 to 48 hours. Ultrathin sections were cut with a Leica Ultramicrotome UCT (Leica Microsystems, Wetzlar, Germany), stained with uranyl acetate, and analyzed with a H7600 transmission electron microscope (Hitachi, Tokyo, Japan).

\section{Cell Assays}

\section{Cytotoxicity Assay}

The cytotoxicity of HpODE was determined for three types of ocular cells: murine photoreceptors, fetal bovine aortic endothelial cells (FBAECs) (passage 3 to passage 8), and human retinal pigment epithelial cells (ARPE19 cells). Photoreceptors were isolated from retinas of passage 2 mice using papain and triturating with siliconized, fire-polished glass pipettes. After plating of 50,000 photoreceptor cells/well in laminin-coated 96-well plates or 15,000 to 20,000 cells/well (FBAECs and ARPE19 cells) on a 24-well plate, cells were allowed to attach. Three different concentrations of HpODE $(60 \mu \mathrm{g} / \mathrm{ml}, 300 \mathrm{ng} / \mathrm{ml}$, and $30 \mathrm{ng} / \mathrm{ml}$ ) or $0.02 \mathrm{~mol} / \mathrm{L}$ sodium borate buffer were added to the wells. After 4, 8, and 24 hours of incubation, photoreceptors were stained with Hoechst 33342 (nu- clei), calcein-AM (detects viable cells), and ethidium homodimer 1 (dead cells). Images were acquired on a Cellomics VTi reader (Thermo Scientific, Pittsburgh, PA) and analyzed using the Target Activation bioapplication. The percentage of Hoechst 33342-stained cells that had a low level of calcein-AM staining and high level of ethidium homodimer staining was determined and considered to represent the percentage of "dead" cells. At the same time points, FBAEC and ARPE19 cell viability was detected using trypan blue (GIBCO, Grand Island, NY). The percentage of cells that were dead (taking up trypan blue) was determined as the number of cells stained with trypan blue/total number of cells in one lowpower field $\times 100(\%)$. Cells in three fields in each well were counted.

\section{Cell Proliferation Assay}

FBEACs and ARPE 19 cells were plated at 20,000 cells/ $\mathrm{ml} /$ well in DMEM/F12 (Dulbecco's modification of Eagle's medium/Ham's F12, Mediatech, Herndon, VA) with 1.5\% fetal bovine serum (FBS) (BD Biosciences, Bedford, MA) and $1 \%$ penicillin-streptomycin (PS) (Invitrogen). For the dose-dependent effect on proliferation, HpODE at 30 $\mu \mathrm{g} / \mathrm{ml}\left(10^{-4} \mathrm{~mol} / \mathrm{L}\right), 3 \mu \mathrm{g} / \mathrm{ml}\left(10^{-5} \mathrm{~mol} / \mathrm{L}\right), 300 \mathrm{ng} / \mathrm{ml}$ ( $\left.10^{-6} \mathrm{~mol} / \mathrm{L}\right), 30 \mathrm{ng} / \mathrm{ml}\left(10^{-7} \mathrm{~mol} / \mathrm{L}\right)$, and $3 \mathrm{ng} / \mathrm{ml}\left(10^{-8}\right.$ $\mathrm{mol} / \mathrm{L})$ was added per well in quadruplicate. DMEM/F12 with $10 \%$ FBS and $1 \%$ PS was used as a positive control. After a 48-hour incubation period, cells were harvested with $0.3 \mathrm{ml}$ of $0.125 \%$ trypsin/EDTA, which was quenched with $0.7 \mathrm{ml}$ of DMEM/F12/10\% FBS. The cell suspension was diluted in Isoton (Nerl Diagnostics, Providence, RI), and cells were counted with a COULTER Z1 counter (Beckman Coulter, Fullerton, CA).

\section{Cell Migration Assay}

The same FBAEC and ARPE19 cell lines were used in a Boyden chamber migration assay. Before the cells were plated, $8-\mu \mathrm{m}$ pore size membranes (Neuro Probe Inc., Gaithersburg, MD) were coated with $100 \mu \mathrm{g} / \mathrm{ml}$ hyaluronic acid (Sigma-Aldrich) and $100 \mu \mathrm{g} / \mathrm{ml}$ fibronectin (GIBCO Life Technologies, Rockville, MD). The bottom wells of the Boyden migration assay chamber (48-Well Micro Chemotaxis Chamber, Neuro Probe Inc.) were filled with medium containing the same concentrations of HpODE as used in the proliferation assay. Minimal es- 
sential medium with 0\% FBS and $1 \%$ PS was used as a negative control and minimal essential medium with $10 \%$ FBS and 1\% PS was used as a positive control. In the upper well, 12,500 cells in $50 \mu$ l of minimal essential medium with $0 \%$ FBS and $1 \%$ PS were plated on the hyaluronic acid/fibronectin-coated membrane. After 8 hours of incubation for FBAECs and 20 hours incubation for ARPE19 cells, the cells that did not migrate through the membrane pores were scraped off. The migrated cells on the bottom of the membrane were fixed in $2 \%$ paraformaldehyde in PBS, stained with 4,6-diamidino-2phenylindole (1:1000, Sigma-Aldrich), and mounted using Dako fluorescent mounting medium (Dako, Carpinteria, CA). Images (three images per well) were captured with an inverted microscope TE2000-U (Nikon, Tokyo, Japan) and converted to binary images with Adobe Photoshop (Photoshop CS, version 8.0), and nuclei were counted using NIH ImageJ software (ImageJ 1.38X).

\section{Statistical Analysis}

Statistical significance of CNV area and cell analysis between the two groups was calculated using an unpaired Student's t-test. We also used a nonparametric, Mann-Whitney $U$-test for the relatively small sample size. For the incidence of CNV, a $\chi^{2}$ test was used. $P<0.05$ was regarded as significant in all comparisons.

\section{Results}

\section{Dose Dependence of CNV Formation after HpODE Injection}

CNV formations were observed using the GSA-lectin flatmount analysis technique in six of seven HpODE (30 $\mu \mathrm{g})$-injected eyes $(85.7 \%, P=0.023)$ and one of five control borate buffer-injected eyes (20\%) at 3 weeks after injection. The new vascular network was clearly demonstrated by GSA-lectin staining in a plane above the RPE (type $2 \mathrm{CNV}$ ) (Figure 1D). This observation was based on confocal microscopic analysis of flatmounted choroids at 3 weeks after the subretinal injection. The lower doses (1, 5, and $15 \mu \mathrm{g}$ ) of HpODE yielded smaller CNV formations (Figure 1, A-C). In addition to the higher incidence of CNV in the high-dose HpODE-injected eye, the CNV area was also greater in high-dose HpODE-injected eyes compared with low-dose HpODE- and vehicle-injected control eyes (Table 3). It seemed that $30 \mu \mathrm{g}$ was the optimal dose of HpODE to stimulate CNV based on the dose dependence study. Usually, there was one CNV formation in the injected area; however, multiple CNV formations were sometimes observed although sizes of CNV in eyes with multiple formations were relatively small (Figure 1C).

\section{Natural Course of HpODE-Induced CNV}

A typical fluorescein angiogram of HpODE-induced CNV showed discrete areas of hyperfluorescence in the early-

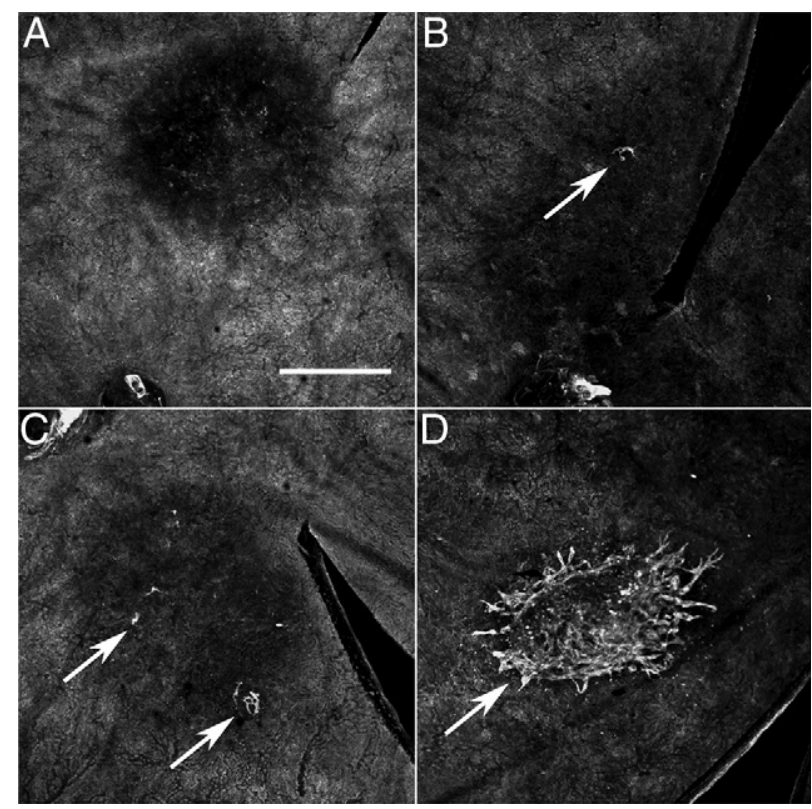

Figure 1. HpODE-induced CNV in flatmount choroids. Flatmount choroids at three weeks after injection were labeled with GSA-lectin to visualize the neovascularization. A: $1 \mu \mathrm{g}$ of HpODE did not induce any demonstrable CNV formations. B and $\mathbf{C}: 5 \mu \mathrm{g}(\mathbf{B})$ and $15 \mu \mathrm{g}(\mathbf{C})$ of HpODE stimulated CNV development (arrows); however, the size of CNV formation was relatively small. D: $30 \mu \mathrm{g}$ of HpODE stimulated well organized CNV formation of substantial size (arrow). Scale bars $=500 \mu \mathrm{m}$.

phase angiogram (Figure 2) and prominent dye leakage was observed in the late-phase angiography (6 to 7 minutes). In general, a small area of dye leakage was observed at 1 week after the injection (Figure 2, A and B, arrow) and was most prominent 3 to 4 weeks after the injection (Figure 2C). At 5 weeks after the injection, which was the longest time point in this study, angiography showed reduced fluorescein leakage (Figure 2D), suggesting the regression or maturation of the CNV.

In the five vehicle-injected eyes embedded in JB4 or LX112 and serial sectioned (Table 1, animals sacrificed at 1 to 5 weeks postinjection), there were no apparent CNV formations nor retinal degeneration after injection (Figure 3, A and D). On the other hand, cross sections of retina from the HpODE-injected eyes showed gradually progressing retinal degeneration in the injected area and growth of CNV into the subretinal space (Figures 4, A-Y, and $5, A-T)$. Retinal degeneration was not observed at 3 days after the injection, but after 1 week, degeneration was seen in the outer nuclear layer (Figures $4 \mathrm{~K}$ and $5 \mathrm{I}$ ). Non-cell-associated von Willebrand factor (vWF) was often observed in the subretinal space at 3 days after

Table 3. CNV Area Measured in Flatmount Choroids

\begin{tabular}{lccr}
\hline Injected material & $\begin{array}{c}\text { No. of } \\
\text { eyes }\end{array}$ & $\begin{array}{c}\text { CNV } \\
\text { (incidence) }\end{array}$ & $\begin{array}{c}\text { Average CNV } \\
\text { area }\left(\mu \mathrm{m}^{2}\right)\end{array}$ \\
\hline HpODE $(30 \mu \mathrm{g})$ & 7 & $6(85.7 \%)$ & 146,475 \\
HpODE $(15 \mu \mathrm{g})$ & 2 & $2(100 \%)$ & 6642 \\
HpODE $(5 \mu \mathrm{g})$ & 3 & $1(33.3 \%)$ & 2107 \\
HpODE $(1 \mu \mathrm{g})$ & 2 & 0 & 0 \\
Borate buffer & 5 & $1(20 \%)$ & 4528 \\
\hline
\end{tabular}

All measurements were taken 3 weeks after the injection. 

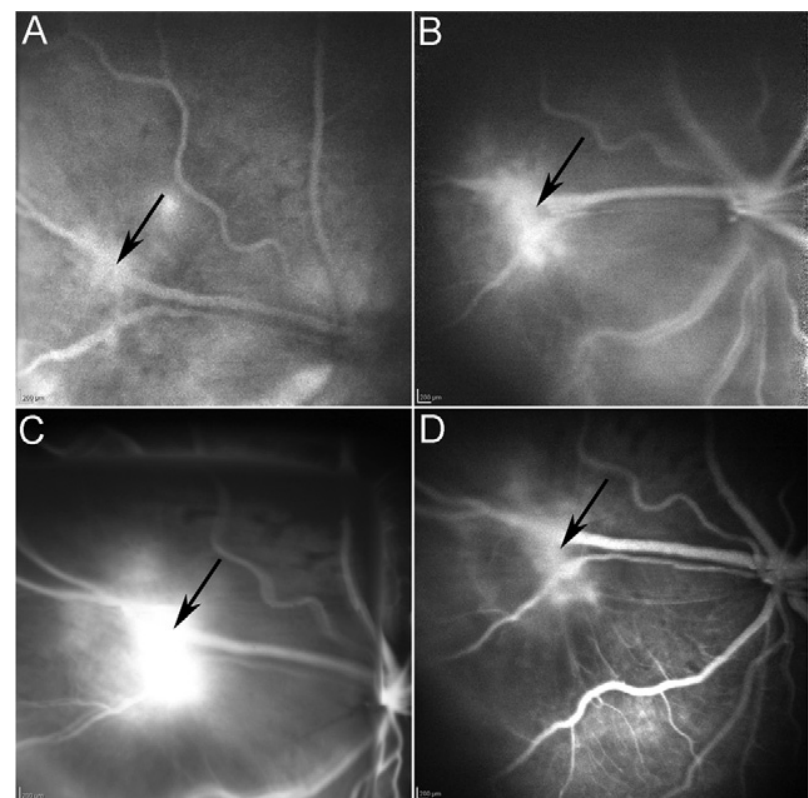

Figure 2. Fluorescein angiography of eye injected with $30 \mu \mathrm{g}$ of HpODE. The time interval in each angiogram was almost the same, approximately 1.5 minutes after the dye injection. A: There was a small dye leakage at one week (arrow). The leakage area was greater at two weeks (B, arrow) and was greatest at three weeks $(\mathbf{C}$, arrow). D: The leakage area decreased at five weeks (arrow).

injection, suggesting a compromised outer blood retinal barrier (Figures $4 \mathrm{H}$ and $5 \mathrm{G}$ ). The nonimmune rabbit IgGincubated sections were negative (results not shown) suggesting that the vWF staining was bona fide. At 3

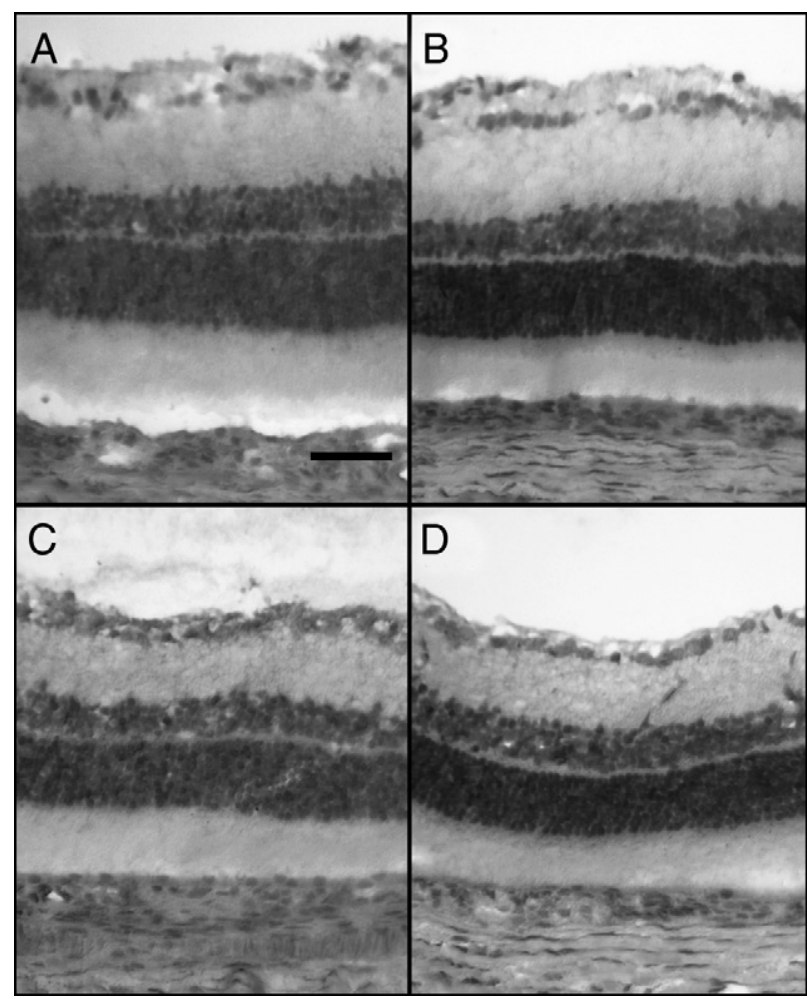

Figure 3. Histology after vehicle injection. There were no apparent changes in tissue morphology after vehicle injection at any time point. A: three days. B: one week. C: two weeks. D: three weeks. PAS and hematoxylin staining. Scale bars $=50 \mu \mathrm{m}$. weeks after the injection, moderate retinal degeneration with substantial CNV formation was observed (Figures $4 \mathrm{~W}$ and 5S).

Oil Red $O$ staining showed that many subretinal cells and RPE cells contained lipids at 3 and 7 days after the injection (Figures 4, G and L, and 5, F and J). At 3 weeks after the injection, abundant lipids were observed in and around the PAS-positive material (Figures 4, U and V, and $5, Q$ and $R$ ) in the area with CNV formations in subretinal space (Figures 4W and $5 \mathrm{~S}$ ).

To investigate whether an inflammatory response was associated with development of CNV, APase immunohistochemistry was performed using inflammatory cell markers. A variety of markers for macrophages, monocytes, and granulocytes were used. At 3 days after the HpODE injection, many cells in the subretinal space were labeled with ED1 antibody and few were labeled with ED2 (Figures 4 , I and $\mathrm{J}$, and $5 \mathrm{H}$ ). This finding suggested a recruitment of circulating macrophages in the early phase. ED2labeled dendritic cells were seen throughout the choroid at all time points, although the number declined with time (Figure 4, J, O, T, and Y). At 7 days after the injection, PAS-positive cells were lined up on BrM and some were ED1-positive (Figures 4, K and N, and 5, I and L). None of these PAS-positive cells had ED2 immunoreactivity after 1 week. Some cells were labeled with circulating macrophage and the monocyte marker ED1 above the CNV visualized with vWF antibody at 3 weeks after HpODE injection (Figures $4 \mathrm{X}$ and $5 \mathrm{~T}$ ), suggesting that the inflammatory reaction remained in the inner retina after the initial infiltration of inflammatory cells. Nonimmune mouse IgG control-incubated sections were negative (results not shown).

Chloroform/methanol extraction of cryosections before staining demonstrated the validity of the Oil Red $\mathrm{O}$ staining. After 30 minutes of extraction, Oil Red $O$ staining in subretinal cells and RPE was eliminated (Figure 6, A-D). This extraction process did not affect the PAS staining of material in these cells (Figure 6).

Serial JB4 sections of HpODE-injected eyes showed that new vessels developed from choriocapillaris and extended through BrM and RPE into the subretinal space (Figure 7, A and B). PAS staining of JB4 sections showed numerous open and thin lumens of new vessels both above and below BrM. The CNV was associated with large PAS-positive cells (Figure 7C, arrow), and a disorganized BrM was observed around the CNV. Polymorphonuclear leukocytes were present in some CNV lumens (Figure 7D). The neural retina at the injected site was disorganized with reduced numbers of nuclei. The retinas of $30-\mu \mathrm{g}$ HpODE-injected eyes were most severely affected and showed progressive degeneration with time (Figure 4).

\section{Ultrastructure after the HpODE Injection}

At 1 week after the injection, there were large cells containing many lipid droplets. The remnants of basal laminar infoldings implied that these are RPE cells (Figure $8 \mathrm{~B})$. The cytoplasm of these cells was filled with electrondense phagosomes and lysosomes (Figure 8A). At 3 


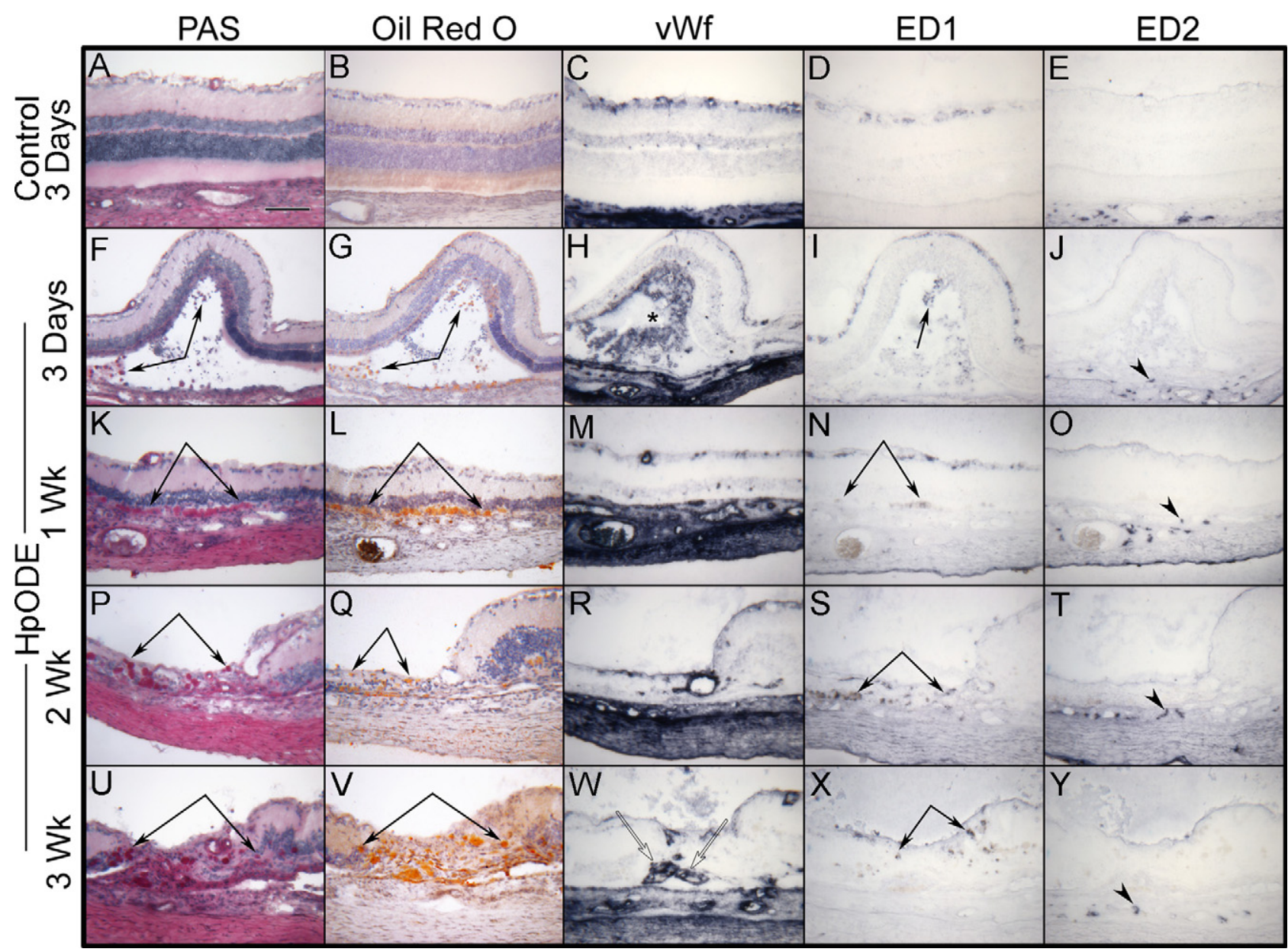

Figure 4. Sections through buffer $(\mathbf{A}-\mathbf{E})$ and HpODE injection sites at three days $(\mathbf{F}-\mathbf{J})$, one week $(\mathbf{K}-\mathbf{O})$, two weeks $(\mathbf{P}-\mathbf{T})$, and three weeks $(\mathbf{U}-\mathbf{Y})$ after injection. $\mathbf{A}$ At three days after vehicle injection, there were no PAS-positive cells. B: Oil Red O staining is present only in photoreceptors. C: The retinal and choroidal vasculature is vWF-positive. There are only a few ED1-positive cells in inner retina (D) and ED2-positive cells in choroid (E). F: At three days after the HpODE injection, the sensory retina was still elevated, and there were many PAS-positive cells (paired arrows). G: Many subretinal cells and RPE cells contained lipids (paired arrows). Immunohistochemistry showed soluble vWF (H, asterisk) in the bleb and subretinal cells labeled with ED1 (I, arrow), whereas only cells in choroid were labeled with ED2 (J, arrowhead). One week after the HpODE injection, there were PAS-positive cells lined up along BrM (K, paired arrows), which contained lipids (L, paired arrows). Some of these cells were ED1-positive (N, paired arrows), and ED2 was present in cells of choroid (O, arrowhead). M: Blood vessels in inner retina, inner nuclear layer of retina, and choroid are labeled for vWf. At two weeks after the HpODE injection, the photoreceptors were degenerated (P paired arrows). There were PAS-positive cells and material in degenerated retina and some lipids (Q, paired arrows). R: Blood vessels in retina and choroid are labled for vWf. Some cells in the retina were labeled with ED1 (S, paired arrows), and ED2-positive cells were restricted to choroid (T, arrowhead). By three weeks there was a robust subretinal CNV clearly labeled with vWF (W, open arrows). PAS-positive material extending horizontally in subretinal space (U, paired arrows), lipids (V, paired arrows), and some ED1-positive cells (X, paired arrows). Y: Only a fewED2-positive cells are present in choroid (arrowhead). Scale bars $=100 \mu \mathrm{m}$.

weeks after the injection, the number of lipid droplets decreased in the cytoplasm of RPE cells. The nuclei of RPE cells were displaced because of the abundant phagosomes (Figure 8B). Other organelles were rarely seen in the expanded cytoplasm. The structure of Bruch's membrane was affected mostly below the lipid-containing RPE cells (Figure $8 \mathrm{C}$ ). New vessels were observed above the degenerated BrM and the choriocapillaris was degenerated with few open lumens (Figure 8D). There were no apparent abnormalities including lipid droplets and RPE changes in control eye (data not shown).

\section{In Vitro Effect of HpODE}

We performed in vitro assays to determine the effects of HpODE on endothelial and RPE cells. No cytotoxicity of FBAECs and ARPE19 cells at any concentration was seen after 4 hours of incubation, although photoreceptors showed about 35\% cell death at this earliest time point (Figure 9A). HpODE at $60 \mu \mathrm{g} / \mathrm{ml}$ caused $67 \%$ of photoreceptors, $96 \%$ of FBEACs, and almost $30 \%$ of ARPE 19 cells to die by 8 hours of incubation. At 24 hours of incubation, $60 \mu \mathrm{g} / \mathrm{ml} \mathrm{HpODE}$ caused $84 \%$ of photoreceptors, $98 \%$ of FBAECs, and $100 \%$ of ARPE19 cells to die. On the other hand, $300 \mathrm{ng} / \mathrm{ml}\left(10^{-6} \mathrm{~mol} / \mathrm{L}\right)$ and $30 \mathrm{ng} / \mathrm{ml}$ $\left(10^{-7} \mathrm{~mol} / \mathrm{L}\right)$ of HpODE did not affect cell viability significantly at 8 and 24 hours, respectively (Figure 9, A-C).

The maximum proliferation of FBAECs was observed with $30 \mathrm{ng} / \mathrm{ml}\left(10^{-7} \mathrm{~mol} / \mathrm{L}\right)(P=0.0253)$ and $3 \mathrm{ng} / \mathrm{ml}$ $\left(10^{-8} \mathrm{~mol} / \mathrm{L}\right) \mathrm{HpODE}(P=0.0148)$. The ARPE19 cells showed the highest proliferation at $300 \mathrm{ng} / \mathrm{ml}\left(10^{-6}\right.$ $\mathrm{mol} / \mathrm{L}) \mathrm{HpODE}(P<0.0001)$. HpODE at $30 \mu \mathrm{g} / \mathrm{ml} \mathrm{dem}-$ onstrated a significant decrease in cell counts of both cell types ( $P=0.0002$ and $P=0.0019$, respectively) suggesting that it was toxic to endothelial and RPE cells after 48 hours of exposure (Figure 10, A and B). 


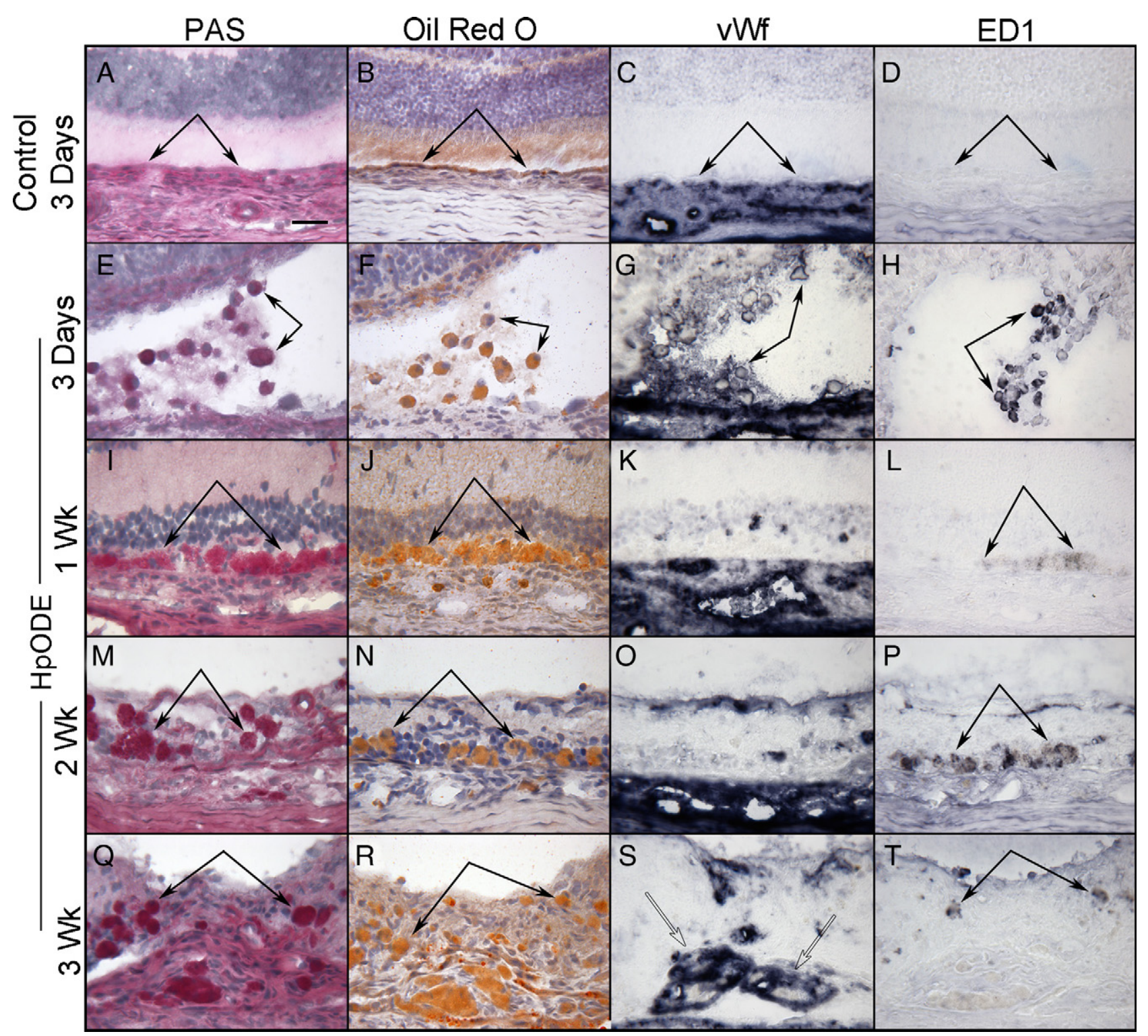

Figure 5. Histochemical staining after buffer (A-D) or HpODE (E-T) injection shown at high magnification. At three days after buffer injection, RPE cells were PAS-positive (A, paired arrows) but contained no lipids (B, paired arrows). There was no VWF (C, paired arrows) nor ED1-positive cells (D, paired arrows) in the subretinal space. E: At three days after the HpODE injection, there were many PAS-positive cells (paired arrows) in the subretinal space. F: Lipids were seen in these cells (paired arrows) and soluble vWF (G, paired arrows) was around the ED1-positive subretinal cells (H, paired arrows). One week after the HpODE injection there were PAS-positive cells lined up along BrM (I, paired arrows) with lipids (J, paired arrows). Some of these cells were ED1-positive (L, paired arrows). K: Some vWf + structures, presumable deep retinal capillaries are present in the inner nuclear layer. M: At two weeks after the HpODE injection, the photoreceptors were degenerated. $\mathbf{M}$ and $\mathbf{N}$ : PAS-positive and lipid-laden cells were in the subretinal space (paired arrows). $\mathbf{O}$ : There is a vWf + structure, presumable a deep retina capillary in what remains of the inner nuclear layer. P: Some subretinal cells labeled with ED1 (paired arrows). S: By three weeks there was a subretinal CNV formation clearly labeled with $\mathrm{vWF}$ (open arrows). PAS-positive material and cells are seen in subretinal space (Q, paired arrows), lipids (R, paired arrows), and some ED1-positive cells ( $T$, paired arrows) above the CNV. Scale bars $=30 \mu \mathrm{m}$.

FBAEC migration over 8 hours was increased, except for cells incubated in $30 \mu \mathrm{g} / \mathrm{ml}\left(10^{-4} \mathrm{~mol} / \mathrm{L}\right) \mathrm{HpODE}$ (Figure 10C). The maximum significant migration through $8-\mu \mathrm{m}$ pores occurred with $300 \mathrm{ng} / \mathrm{ml}\left(10^{-6} \mathrm{~mol} / \mathrm{L}\right)$ HpODE $(P=0.0014)$. There was also a significant increase in migration with $30 \mathrm{ng} / \mathrm{ml}\left(10^{-7} \mathrm{~mol} / \mathrm{L}\right)$ and 3 $\mathrm{ng} / \mathrm{ml}\left(10^{[8} \mathrm{mol} / \mathrm{L}\right)$ of HpODE $(P=0.0006$ and $P=$ 0.0262 , respectively). On the other hand, ARPE19 cells did not show significant migration in this assay after 20 hours of incubation with any concentration of HpODE (Figure 10D).

\section{Discussion}

The current study demonstrates that the lipid hydroperoxide $\mathrm{HpODE}$ can induce retinal degeneration and subsequently choroidal neovascularization. The subretinally injected HpODE seems to first attract infiltrating white blood cells, and then outer retinal degeneration ensues (Figure 11, A-F). RPE cells phagocytose the HpODE and some detach from BrM, causing breakdown of the outer retinal barrier. Either the HpODE-laden RPE cells or infiltrating cells or the $\mathrm{HpODE}$ itself directly stimulate the formation of CNV. 


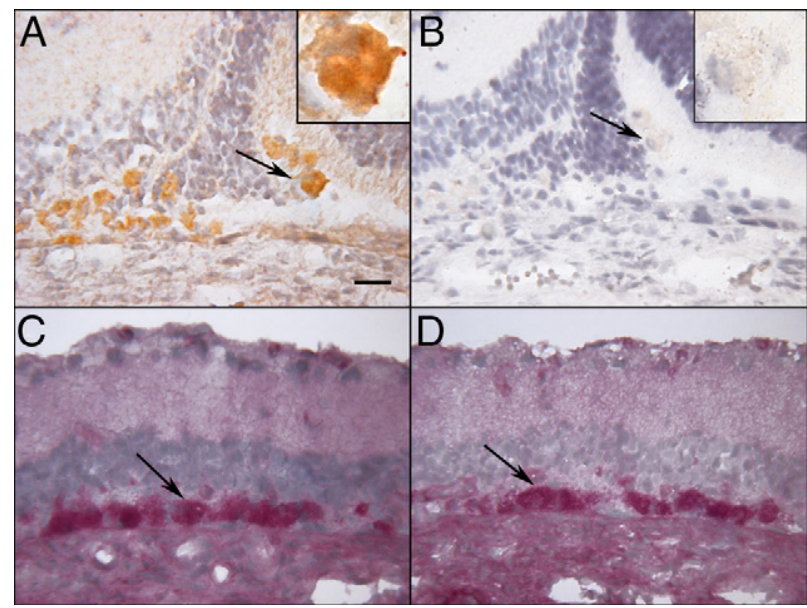

Figure 6. Extraction of lipids with chloroform-methanol. A: Oil Red O staining of lipids in RPE and monocytes (arrow, inset at higher magnification) at an injection site at seven days after injection of HpODE. B: A seria section to the one shown in $\mathbf{A}$, which was extracted with chloroform methanol and then stained with Oil Red O. The extraction process has removed all of the Oil Red O-stained lipids from the section in both RPE cells and monocytes (arrow, inset). C: PAS staining of a serial section. D: PAS staining of a serial section after chloroform/methanol extraction shows PASpositive cells along BrM (arrow). No PAS-positive material is eliminated by the extraction process (arrow). Hematoxylin counterstaining in all. Scale bars $=20 \mu \mathrm{m}$

The peroxidized lipid injected subretinally in this model was identified in aged human BrM. ${ }^{9}$ Peroxidized lipids are reactive compounds capable of interacting with each other or with neighboring lipids and proteins. HpODE can form 4-hydroxy-2,3-trans-nonenal after several steps in vivo: reduction, complement factor $\mathrm{H}$ abstraction, and isomerization. 4-Hydroxy-2,3-trans-nonenal has been shown to be chemotactic for rat neutrophils and can stimulate guanylate cyclase and phospholipase C activity at low dose in some cells but is cytotoxic to endothelial cells at higher doses. ${ }^{20}$

The angiogenic effect of the HpODE injection may be stimulation of endothelial cells directly (Figure 10). In angiogenesis, endothelial cells first migrate and then pro-

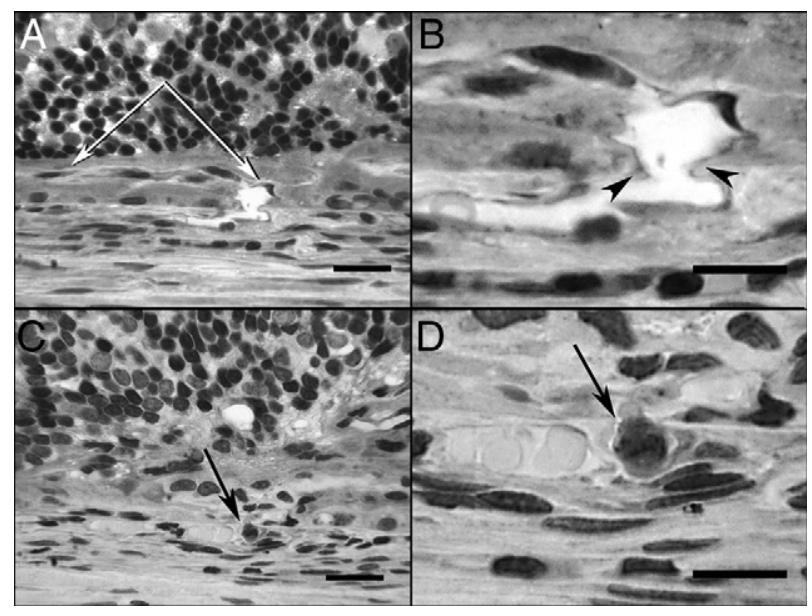

Figure 7. CNV in JB4 sections. CNV formations (A, paired arrows) growing from choriocapillaris through $\mathrm{BrM}(\mathbf{B}$, arrowheads) into the subretinal space at three weeks after a 30- $\mu \mathrm{g}$ HpODE injection. $\mathbf{C}$ and D: A polymorphonuclear leukocyte is present in the CNV lumen (arrow). PAS and hematoxylin staining. Scale bar: $20 \mu \mathrm{m}(\mathbf{A}$ and $\mathbf{C}) ; 10 \mu \mathrm{m}(\mathbf{B}$ and $\mathbf{D})$.

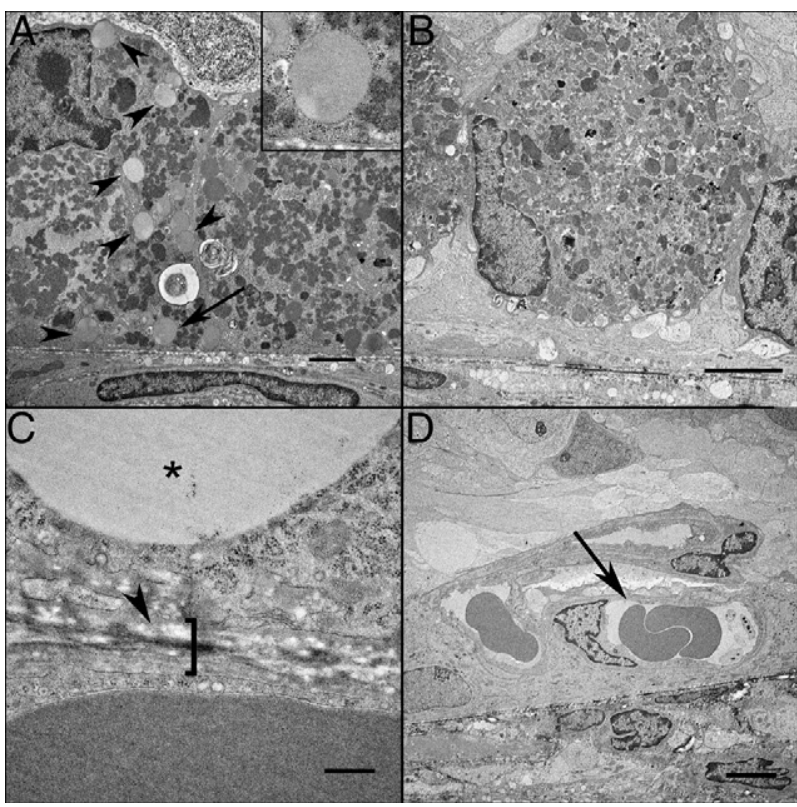

Figure 8. Ultrastructure after HpODE injection. A: At one week, the RPE cells contained many lipid droplets (arrowheads). The arrow indicates the large lipid droplet in the inset. The photoreceptors were degenerated at this site. B: At three weeks, there were fewer large lipid droplets in the RPE cell. C: Degeneration (arrowhead) and disorganization (bracket) of BrM were observed close to a lipid droplet (asterisk). D: The new vessels located just above BrM showed open lumens containing red blood cells (arrow). Scale bars: $2 \mu \mathrm{m}(\mathbf{A}) ; 4 \mu \mathrm{m}(\mathbf{B}) ; 500 \mathrm{~nm}(\mathbf{C}) ; 4 \mu \mathrm{m}(\mathbf{D})$

liferate to create the new blood vessels. We demonstrate that HpODE stimulates both endothelial cell migration and proliferation as reported previously by Yamada et al. ${ }^{21}$ However, if the dose was too high, HpODE was toxic to the endothelial cells, RPE cells, and photoreceptors.

In vivo, HpODE stimulated inflammation initially and angiogenesis at later time points. Inflammation is now thought to be a key event in human AMD, in which mutations in complement factor $\mathrm{H}$, the inhibitory side of complement, is a major risk factor for both wet and dry AMD. ${ }^{22-25}$ HpODE injected subretinally seems to be a chemoattractant for leukocytes. Whether it is a direct chemoattractant or whether leukocytes are responding to death of photoreceptors is unclear at this time. In addition, RPE cells are known to attract macrophages by secreting monocyte chemoattractant protein. ${ }^{26}$ We found ED1-positive circulating monocytes and very limited numbers of ED2-positive resident macrophages in the subretinal space at early time points after HpODE injection. These macrophages can secrete vascular growth factors (Figure 11E), phagocytose HpODE (Figure 11D), and damage BrM via increased matrix metalloproteinase activity. ${ }^{27}$

The most commonly used model for CNV is the laserinduced model developed initially in Ryan's laboratory. In the acute phase after injury, macrophages are recruited into the injury site. ${ }^{28}$ About $70 \%$ of macrophages in laserinduced CNV were reported to be derived from bone marrow, ${ }^{29}$ which is comparable with our result with subretinal HpODE, where abundant ED1-positive cells are present at 3 days after the injection (Figure 4). On the other hand, ED2-positive resident macrophages did not 
A

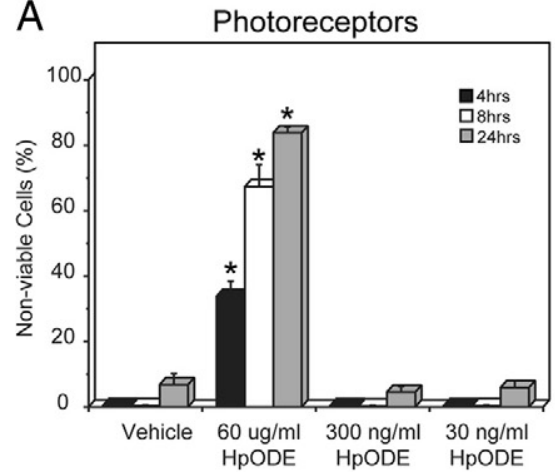

B

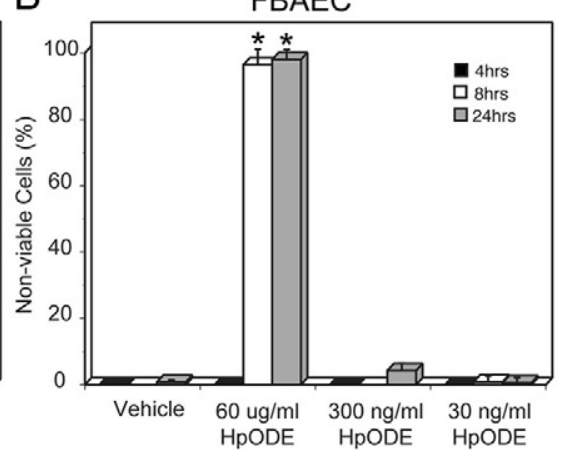

C

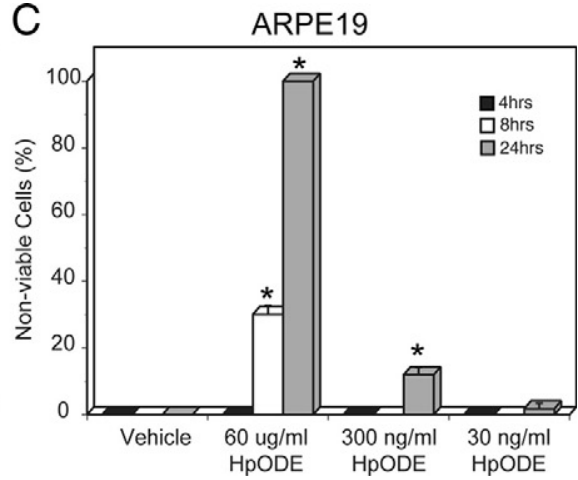

Figure 9. HpODE dose-dependent cytotoxicity: photoreceptors (A), FBAECs (B), and ARPE19 cells (C). A-C: Although the lower concentrations of HpODE showed minimal cytotoxicity, $60 \mu \mathrm{g} / \mathrm{ml} \mathrm{HpODE}$ was clearly cytotoxic. The photoreceptors, which started to die as early as four hours, were most vulnerable to high-dose $\operatorname{HpODE}(\mathbf{A}) .{ }^{*} P=0.05$.

seem to contribute to development of HpODE-induced CNV, because no ED2-positive cells were present in the subretinal space. This finding is comparable to human AMD, as reported by Sakurai et al, ${ }^{30}$ in which microglia have not been reported to be associated with CNV but circulating leukocytes may contribute. However, Gupta et $\mathrm{al}^{31}$ identified outer retinal microglia in their series of AMD eyes using Ricinus communis agglutinin-1 lectin. Recruitment of monocytes is common during the first 48 hours after photocoagulation ${ }^{32}$ when angiogenic factors (vascular endothelial growth factor [VEGF] and basic fibroblast growth factor) and proinflammatory cytokines (tumor necrosis factor- $\alpha$ ) were elevated in the laser model. However, there has been no report on infiltration of cells in the late stage of the experimental laser CNV model; we observed retention of white blood cells with time in the HpODE model. In human AMD, a chronic inflammatory reaction has been related to the development of $\mathrm{CNV},{ }^{33}$ and ED1-positive macrophages have been observed in and around CNV of patients with late-stage AMD. ${ }^{34} \mathrm{Al}-$ though the inflammatory cells in our model were probably a mixture of several subtypes of leukocytes, the inflammatory aspects of the HpODE-induced model and also the laser model mimic human wet AMD in some aspects.

For CNV to form, BrM must have a defect for the endothelial cells to migrate through. In the HpODE model of CNV, BrM is not broken surgically. In fact, all animals with subretinal hemorrhage were presumed to have BrM disruption and were not used in the study. We found in our preliminary studies that just damaging BrM can stimulate CNV formation; $100 \%$ of the eyes with hemorrhage after subretinal vehicle injection had CNV. However, the new vessels regressed rapidly in these control eyes without a supply of HpODE, a potential angiogenic factor. There were no CNV formations in buffer controls without BrM being damaged. In the laser-induced CNV model, the disruption of BrM was reported to be necessary for development of CNV. ${ }^{12}$ Collectively, damage to BrM plays a critical role in CNV formation. Because we did not observe subretinal hemorrhage in the animals included in
A

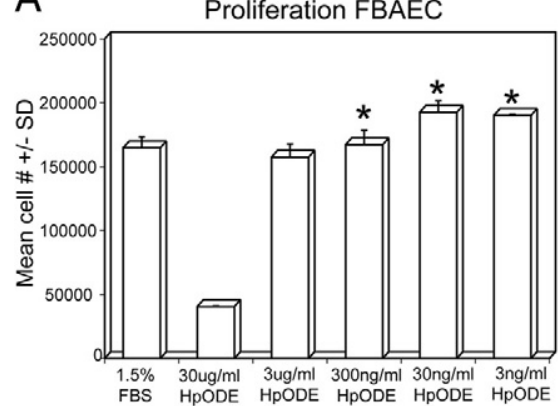

C

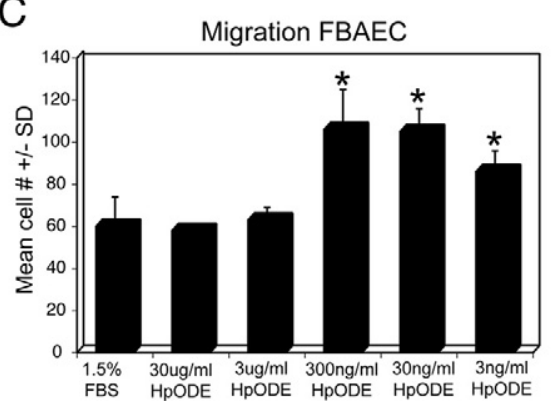

B
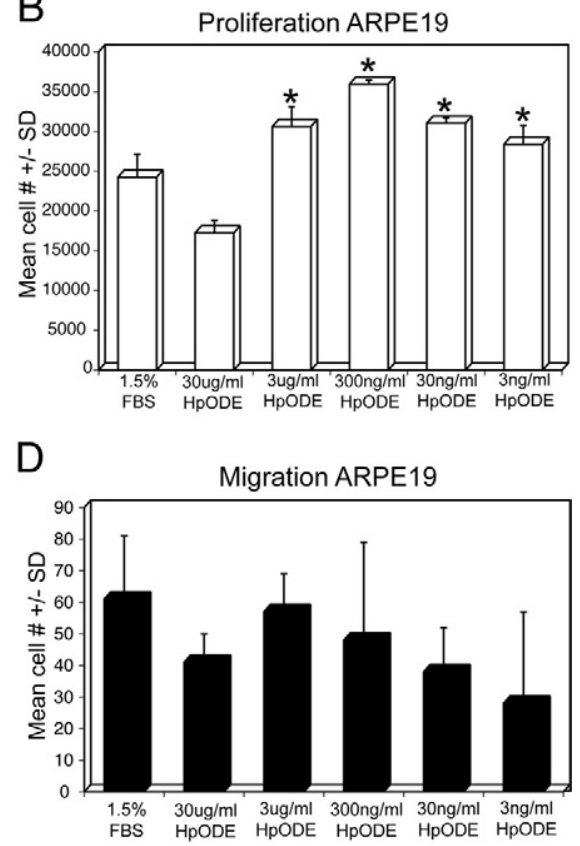

Figure 10. HpODE effects on cell proliferation and migration. A: Proliferation assay, FBAECs. B: Proliferation assay, ARPE19 cells. C: Migration assay, FBAECs. D: Migration assay, ARPE19 cells. HPODE doses from 300 to $3 \mathrm{ng} / \mathrm{ml}$ produced significant cell proliferation of FBAECs and ARPE19 cells. A and B: $30 \mu \mathrm{g} / \mathrm{ml}$ HpODE showed a negative effect on cell proliferation because of its cytotoxicity. C and $\mathbf{D}$ : HPODE stimulated FBAEC migration at concentrations of 300 to $3 \mathrm{ng} / \mathrm{ml}$ (C) but did not stimulate a significant increase in ARPE19 cell migration (D). ${ }^{*} P=0.05$. 


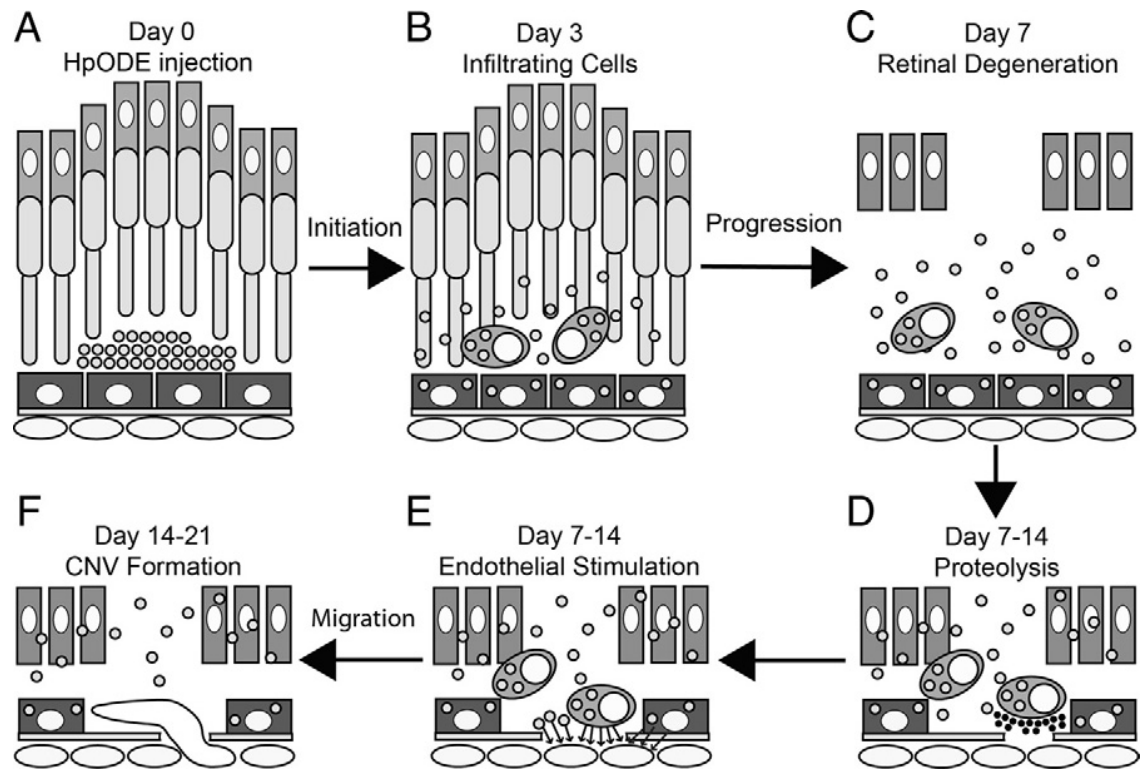

Figure 11. Schematic diagram showing the proposed model of development of $\mathrm{CNV}$ induced by HpODE. HpODE injected subretinally (A) disperses and initiates the infiltration of macrophages and other inflammatory cells (B). Inflammatory cells and RPE phagocytose the HpODE (B). Progressive retinal degeneration begins in photoreceptor layer seven days after the HpODE injection (C). Proteolysis via the infiltrated cells degrades Bruch's membrane (D). At seven to 14 days, the infiltrated and RPE cells stimulate migration and proliferation of choriocapillaris endothelial cells by secreting growth factors (E) The HpODE itself might stimulate endothelia cell proliferation and migration. Finally, CNV grows through Bruch's membrane into the subretinal space $(\mathbf{F})$

that study when we injected HpODE, the initial damage to BrM seems to be minimal in our model. Therefore, the effect of HpODE may be to stimulate leukocytes or RPE to produce proteases, which degrade BrM (Figure 1D). On the other hand, the HpODE may stimulate the endothelial cells to produce proteases that degrade BrM and make their migration through it possible.

Our in vitro studies suggest that HpODE itself may be the stimulus for angiogenesis. After intravitreal injection of HpODE in rabbit, angiogenic (VEGF, basic fibroblast growth factor, and pigment epithelium-derived factor) and proinflammatory factors (tumor-necrosis factor- $\alpha$ and interleukin-1) were elevated. ${ }^{35}$ The source of these cytokines was not elucidated in that report, but the results supports our result in terms of the angiogenic event occurring in the subretinal space after HpODE injection. Perhaps the leukocytes that migrate into the injection site produce angiogenic factors when stimulated by HpODE. Macrophages and/or neutrophils seem to provide VEGF in the experimental laser CNV model. ${ }^{36-38}$ RPE cells also secrete angiogenic factors, and HpODE may increase their secretion of angiogenic factors based on our result that HpODE stimulates RPE proliferation. Yamada et $\mathrm{al}^{21}$ found that HpODE stimulated secretion of basic fibroblast growth factor by bovine aortic endothelial cells, suggesting that HpODE stimulates autocrine induction of vascular endothelial proliferation. Maharaj et al, ${ }^{39}$ however, found that endothelial cells were a minor source of VEGF and other angiogenic growth factors compared with macrophages, neutrophils, and RPE cells. ${ }^{39}$ Regardless of the source of angiogenic factors, HpODE-induced CNV was apparent and showed prominent dye leakage by fluorescein angiography at 1 week. The leakage increased through the first 3 weeks after the injection and declined thereafter. The viability of the CNV formations observed in the HpODE-induced model is longer than that in the laser-induced CNV model, in which CNV regresses mostly in first 3 weeks. Because the laser-induced CNV occurs by a wound-healing process, CNV regresses when the laser wound has healed and scar has formed. 6

In the HpODE-induced CNV model, severe retinal degeneration was observed. The photoreceptor layer was first affected, then degeneration involved the inner nuclear layer, and finally the full thickness of retina was affected. Curcio et $\mathrm{al}^{40}$ found that photoreceptors die early in human AMD eyes and rods are affected more severely than cones. The reason that AMD causes retinal degeneration has not been elucidated, but the chronic inflammation and accumulation of subretinal fluid is thought to cause dysfunction of neural retina. ${ }^{41}$ In our model, the retinal degeneration occurred much earlier in the disease process than in human AMD. The explanation for this difference is probably the toxicity of HpODE itself on photoreceptor cells. The photoreceptors were affected as early as 4 hours after the exposure to HpODE based on our in vitro analysis.

The distribution of HpODE in this model after the subretinal injection is similar to the accumulation in human AMD. Yamada et $a^{42}$ localized oxidized lipids to Bruch's membrane. ${ }^{42}$ Suzuki et $\mathrm{al}^{43}$ showed an age-related increase in accumulation of oxidized phospholipids in photoreceptors and RPE cells in the macula of human donor eyes. The scavenger receptors for oxidized lipoprotein were found in macrophages and RPE cells in surgically excised CNV membrane. ${ }^{44}$ In the HpODE-induced CNV model, we observed lipid granules in infiltrating macrophages and RPE cells by Oil Red O staining. In human AMD, these two cell types have been reported as major sources of VEGF and other angiogenic factors. ${ }^{26,34,45}$ Perhaps the lipid-laden cells in our rat model are activated and are a source of angiogenic factors.

In conclusion, many morphological features of HpODEinduced CNV are quite similar to those of human dry AMD initially: RPE loss, inflammatory infiltrate, and photoreceptor degeneration. Secondarily, it is similar to wet AMD: CNV and subretinal fluid accumulation. However, it is unlike human AMD in that photoreceptor degeneration is 
the initial event and drusen and basal linear and laminar deposits were never observed. In human AMD, the lipid hydroperoxides are within Bruch's membrane, whereas in the model they have been added exogenously. The model is similar to that created by Tamai et al ${ }^{10}$ in rabbit. However, we have used rat, making the model more affordable, and defined the time course and mechanisms for the disease processes in the model. We have identified the infiltrating cells as macrophages and observed that these cells and RPE cells accumulate large amounts of lipids. Unlike Tamai et al, we were able to quantify the CNV area in flatmounts and determine the CNV permeability and longevity. We have further determined that the lipid is cytotoxic to neurons, RPE, and endothelial cells at high doses and angiogenic (stimulates migration and proliferation) at lower doses in vitro. Moreover, HpODEinduced CNV in rat was highly reproducible and its natural course was ideal for evaluating therapeutic modalities as reported previously in a rat model for retinal neovascularization. ${ }^{46}$ The HpODE-induced rat model seems to be a good model for human AMD because HpODE has been isolated from aged human and the model has pathological features similar to both dry and wet AMD.

\section{Acknowledgments}

We are grateful to Cindy Berlinicke and Gillian Shaw for the cytotoxicity assay using photoreceptors.

\section{References}

1. Ambati J, Ambati B, Yoo S, lanchulev S, Adamis A: Age-related macular degeneration: etiology, pathogenesis, and therapeutic strategies. Surv Ophthalmol 2003, 48:257-293

2. Green WR, Enger C: Age-related macular degeneration histopathologic studies. Ophthalmology 1993, 100:1519-1535

3. Sarks SH: Aging and degeneration in the macular region: a clinicopathological study. Br J Ophthal 1976, 60:324-341

4. Ryan SJ: The development of an experimental model of subretinal neovascularization in disciform macular degeneration. Trans Am Ophthalmol Soc 1979, 77:707-745

5. Goldberg MF: Editorial: Bruch's membrane and vascular growth. Invest Ophthalmol 1976, 15:443-446

6. Fukushima I, Kusaka K, Takahashi K, Kishimoto N, Nishimura T, Ohkuma H, Uyama M: Comparison of indocyanine green and fluorescein angiography of choroidal neovascularization. Jpn J Ophthalmol 1997, 41:284-296

7. Curcio CA, Johnson M, Huang JD, Rudolf M: Aging, age-related macular degeneration, and the response-to-retention of apolipoprotein B-containing lipoproteins. Prog Retin Eye Res 2009, 28:393-422

8. Wang L, Li CM, Rudolf M, Belyaeva OV, Chung BH, Messinger JD, Kedishvili NY, Curcio CA: Lipoprotein particles of intraocular origin in human Bruch membrane: an unusual lipid profile. Invest Ophthalmol Vis Sci 2009, 50:870-877

9. Spaide RF, Ho-Spaide WC, Browne RW, Armstrong D: Characterization of peroxidized lipids in Bruch's membrane. Retina 1999, 19:141-147

10. Tamai K, Spaide RF, Ellis EA, Iwabuchi S, Ogura Y, Armstrong D: Lipid hydroperoxide stimulates subretinal choroidal neovascularization in the rabbit. Exp Eye Res 2002, 74:301-308

11. Armstrong D, Hiramitsu T, Gutteridge J, Nilsson SE: Studies on experimentally induced retinal degeneration. 1. Effect of lipid peroxides on electroretinographic activity in the albino rabbit, Exp Eye Res 1982, 35:157-171

12. Campos M, Amaral J, Becerra SP, Fariss RN: A novel imaging tech- nique for experimental choroidal neovascularization. Invest Ophthalmol Vis Sci 2006, 47:5163-5170

13. Lutty GA, Merges C, Threlkeld AB, Crone S, McLeod DS: Heterogeneity in localization of isoforms of TGF- $\beta$ in human retina, vitreous, and choroid. Invest Ophthalmol Vis Sci 1993, 34:477-487

14. Malek G, Li C-M, Guidry C, Medeiros N, Curcio C: Apolipoprotein B in cholesterol-containing drusen and basal deposits of human eyes with age-related maculopathy. Am J Pathol 2003, 162:413-425

15. Bhutto IA, Kim SY, McLeod DS, Merges CA, Fukai N, Olsen BR, Lutty GA: Localization of collagen XVIII and the endostatin portion of collagen $\mathrm{XVIII}$ in aged human control eyes and eyes with age-related macular degeneration. Invest Ophthalmol Vis Sci 2004, 45:1544-1552

16. Dijkstra CD, Dopp EA, Joling P, Kraal G: The heterogeneity of mononuclear phagocytes in lymphoid organs: distinct macrophage subpopulations in the rat recognized by monoclonal antibodies ED1. ED2 and ED3, Immunology 1985, 54:589-599

17. McMenamin PG, Crewe J, Morrison S, Holt PG: Immunomorphologic studies of macrophages and MHC class II-positive dendritic cells in the iris and ciliary body of the rat, mouse, and human eye. Invest Ophthalmol Vis Sci 1994, 35:3234-3250

18. Damoiseaux JG, Dopp EA, Neefjes JJ, Beelen RH, Dijkstra CD: Heterogeneity of macrophages in the rat evidenced by variability in determinants: two new anti-rat macrophage antibodies against a heterodimer of 160 and 95 kd (CD11/CD18). J Leukoc Biol 1989, 46:556-564

19. Sadler JE: Biochemistry and genetics of von Willebrand factor. Annu Rev Biochem 1998, 67:395-424

20. Esterbauer $\mathrm{H}$, Schaur RJ, Zollner $\mathrm{H}$ : Chemistry and biochemistry of 4-hydroxynonenal, malonaldehyde and related aldehydes. Free Radic Biol Med 1991, 11:81-128

21. Yamada Y, Nakanishi-Ueda T, Yasuda M, Armstrong D, Yamamoto Y, Yamamoto T, Yashuhara H: Angiogenic effect of lipid hydroperoxide on bovine aortic endothelial cells. J Clin Biochem Nutr 1998, 25:122-130

22. Edwards AO, Ritter R 3rd, Abel KJ, Manning A, Panhuysen C, Farrer LA: Complement factor $\mathrm{H}$ polymorphism and age-related macular degeneration. Science 2005, 308:421-424

23. Hageman GS, Anderson DH, Johnson LV, Hancox LS, Taiber AJ, Hardisty LI, Hageman JL, Stockman HA, Borchardt JD, Gehrs KM, Smith RJ, Silvestri G, Russell SR, Klaver CC, Barbazetto I, Chang S, Yannuzzi LA, Barile GR, Merriam JC, Smith RT, Olsh AK, Bergeron J, Zernant J, Merriam JE, Gold B, Dean M, Allikmets R: A common haplotype in the complement regulatory gene factor $\mathrm{H}(\mathrm{HF} 1 / \mathrm{CFH})$ predisposes individuals to age-related macular degeneration. Proc Natl Acad Sci USA 2005, 102:7227-7232

24. Haines JL, Hauser MA, Schmidt S, Scott WK, Olson LM, Gallins P, Spencer KL, Kwan SY, Noureddine M, Gilbert JR, Schnetz-Boutaud N, Agarwal A, Postel EA, Pericak-Vance MA: Complement factor $\mathrm{H}$ variant increases the risk of age-related macular degeneration. Science 2005, 308:419-421

25. Klein RJ, Zeiss C, Chew EY, Tsai JY, Sackler RS, Haynes C, Henning AK, SanGiovanni JP, Mane SM, Mayne ST, Bracken MB, Ferris FL, Ott J, Barnstable C, Hoh J: Complement factor $\mathrm{H}$ polymorphism in agerelated macular degeneration. Science 2005, 308:385-389

26. Grossniklaus HE, Ling JX, Wallace T, M, Dithmar S, Lawson DH, Cohen C, Elner VM, Elner SG, Sternberg P: Macrophage and retinal pigment epithelium expression of angiogenic cytokines in choroidal neovascularization. Mol Vis 2002, 8:119-126

27. Iwai S, Aljada A, Higa A, Nakanishi-Ueda T, Fukuda S, Kamegawa M Iwabuchi S, Ueda T, Caballero S, Browne R, Afzal A, Grant M, Yasuhara H, Koide R, Oguchi K, Dandona P, Armstrong D: Activation of AP-1 and increased synthesis of MMP-9 in the rabbit retina induced by lipid hydroperoxide. Curr Eye Res 2006, 31:337-346

28. Ishibashi T, Miller H, Orr G, Sorgente N, Ryan SJ: Morphologic observations on experimental subretinal neovascularization in the monkey. Invest Ophthalmol Vis Sci 1987, 28:1116-1130

29. Espinosa-Heidmann DG, Reinoso MA, Pina Y, Csaky KG, Caicedo A, Cousins SW: Quantitative enumeration of vascular smooth muscle cells and endothelial cells derived from bone marrow precursors in experimental choroidal neovascularization. Exp Eye Res 2005, 80:369-378

30. Sakurai E, Anand A, Ambati BK, van Rooijen N, Ambati J: Macrophage depletion inhibits experimental choroidal neovascularization. Invest Ophthalmol Vis Sci 2003, 44:3578-3585 
31. Gupta N, Brown KE, Milam AH: Activated microglia in human retinitis pigmentosa, late-onset retinal degeneration, and age-related macular degeneration. Exp Eye Res 2003, 76:463-471

32. Tsutsumi C, Sonoda KH, Egashira K, Qiao H, Hisatomi T, Nakao S, Ishibashi M, Charo IF, Sakamoto T, Murata T, Ishibashi T: The critical role of ocular-infiltrating macrophages in the development of choroidal neovascularization. J Leukoc Biol 2003, 74:25-32

33. Donoso LA, Kim D, Frost A, Callahan A, Hageman G: The role of inflammation in the pathogenesis of age-related macular degeneration. Surv Ophthalmol 2006, 51:137-152

34. Oh H, Takagi $H$, Takagi $C$, Suzuma K, Otani A, Ishida K, Matsumura M, Ogura Y, Honda Y: The potential angiogenic role of macrophages in the formation of choroidal neovascular membranes. Invest Ophthalmol Vis Sci 1999, 40:1891-1898

35. Armstrong D, Ueda T, Ueda T, Aljada A, Browne R, Fukuda S, Spengler R, Chou R, Hartnett M, Buch P, Dandona P, Sasisekharan R, Dorey CK: Lipid hydroperoxide stimulates retinal neovascularization in rabbit retina through expression of tumor necrosis factor- $\alpha$, vascular endothelial growth factor and platelet-derived growth factor. Angiogenesis 1998, 2:93-104

36. Tsutsumi-Miyahara C, Sonoda KH, Egashira K, Ishibashi M, Qiao H, Oshima T, Murata T, Miyazaki M, Charo IF, Hamano S, Ishibashi T: The relative contributions of each subset of ocular infiltrated cells in experimental choroidal neovascularisation. $\mathrm{Br} J$ Ophthalmol 2004, 88:1217-1222

37. Yi X, Ogata N, Komada M, Yamamoto C, Takahashi K, Omori K, Uyama M: Vascular endothelial growth factor expression in choroidal neovascularization in rats. Graefes Arch Clin Exp Ophthalmol 1997. 235:313-319

38. Zhou J, Pham L, Zhang N, He S, Gamulescu MA, Spee C, Ryan SJ,
Hinton DR: Neutrophils promote experimental choroidal neovascularization. Mol Vis 2005, 11:414-424

39. Maharaj AS, Saint-Geniez M, Maldonado AE, D'Amore PA: Vascular endothelial growth factor localization in the adult. Am J Pathol 2006, 168:639-648

40. Curcio CA, Medeiros NE, Millican CL: Photoreceptor loss in age-related macular degeneration. Invest Ophthal Vis Sci 1996, 37:1236-1249

41. Xu GZ, Li WW, Tso MO: Apoptosis in human retinal degenerations. Trans Am Ophthalmol Soc 1996, 94:411-431

42. Yamada Y, Tian J, Yang Y, Cutler RG, Wu T, Telljohann RS, Mattson MP, Handa JT: Oxidized low density lipoproteins induce a pathologic response by retinal pigmented epithelial cells. J Neurochem 2008 , 105:1187-1197

43. Suzuki M, Kamei M, Itabe H, Yoneda K, Bando H, Kume N, Tano Y: Oxidized phospholipids in the macula increase with age and in eyes with age-related macular degeneration. Mol Vis 2007, 13:772-778

44. Kamei M, Yoneda K, Kume N, Suzuki M, Itabe $H$, Matsuda K, Shimaoka T, Minami M, Yonehara S, Kita T, Kinoshita S: Scavenger receptors for oxidized lipoprotein in age-related macular degeneration. Invest Ophthalmol Vis Sci 2007, 48:1801-1807

45. Bhutto IA, McLeod DS, Hasegawa T, Kim SY, Merges C, Tong P, Lutty GA: Pigment epithelium-derived factor (PEDF) and vascular endothelial growth factor (VEGF) in aged human choroid and eyes with age-related macular degeneration. Exp Eye Res 2006, 82:99-110

46. Matsubara A, Tamai K, Matsuda Y, Niwa Y, Morita H, Tomida K Armstrong D, Ogura Y: Protective effect of polyethylene glycol-superoxide dismutase on leukocyte dynamics in rat retinal microcirculation under lipid hydroperoxide-induced oxidative stress. Exp Eye Res 2005, 81:193-199 